\title{
RADICALIDAD DEMOCRÁTICA Y NUEVOS MOVIMIENTOS POPULARES: LAS LUCHAS POR OTRAS DEMOCRACIAS ${ }^{1}$
}

\author{
Antoni Jesús Aguiló Bonet \\ Centro de Estudos Socias da Universidade de Coimbra
}

RESUMEN: El objetivo principal de este artículo es explorar el nuevo sentido común democrático forjado por los movimientos contemporáneos por la democracia real en el contexto de la crisis de la democracia representativa liberal y de las luchas contra la crisis económica mundial y sus efectos. Los movimientos por la democracia real son portadores de lenguajes y prácticas democráticas que desafían las formas tradicionales de concebir y hacer política e introducen formas renovadas de participación, acción y movilización colectiva que pueden contribuir a la creación de sentidos comunes políticos en un horizonte de democracia radical, experimentalismo y demodiversidad.

Palabras clave: indignación, movimientos sociales, democracia, política en las calles.

RESUM: L'objectiu principal d'aquest article és explorar el nou sentit comú democràtic forjat pels moviments contemporanis per la democràcia real en el context de la crisi de la democràcia representativa liberal i de les lluites contra la crisi econòmica mundial i els seus efectes. Els moviments per la democràcia real són portadors de llenguatges i pràctiques democràtiques que desafien les formes tradicionals de concebre i fer política i introdueixen formes renovades de participació, acció i mobilització col·lectiva que poden contribuir a la crea-

1. Este trabajo ha sido desarrollado en el ámbito del proyecto «ALICE - Espejos extraños, lecciones imprevistas: definiendo para Europa una nueva manera de compartir las experiencias del mundo» (alice.ces.uc.pt), coordinado por Boaventura de Sousa Santos en el Centro de Estudios Sociales de la Universidad de Coímbra (Portugal). El proyecto recibe fondos del Consejo Europeo de Investigación a través del séptimo Programa Marco de la Unión Europea (FP/2007-2013) / ERC Grant Agreement nº 269807. 
ció de sentits comuns polítics en un horitzó de democràcia radical, experimentalisme i demodiversitat.

Paraules clau: indignació, moviments socials, democràcia, política als carrers.

ABSTRACT: The main aim of this paper is to explore the new democratic common sense forged by contemporary movements for real democracy in the context of the crisis of liberal representative democracy and the struggle against the global economic crisis and its effects.

The movements for real democracy bring with them democratic languages and practices that challenge dominant ways of thinking and doing politics, and introduce renewed forms of participation, social mobilisation and collective action. These can contribute to creating counter-hegemonic political common senses against a horizon of radical democratisation, demo-diversity and experimentalism.

KeYWORDs: outrage, social movements, democracy, politics in the streets.

\section{Indignación y política en las calles}

$\mathrm{N}$ o cabe duda de que la democracia real se ha convertido en una de las grandes aspiraciones colectivas del actual «ciclo de protesta» ${ }^{2}$ y movilización (Tarrow, 2004); una aspiración que se manifiesta de las maneras más

2. Tarrow (2004: 202-203) define un ciclo de protesta como «una fase de intensificación de los conflictos y la confrontación en el sistema social, que incluye una rápida difusión de la acción colectiva de los sectores más movilizados a los menos movilizados; un ritmo de innovación acelerado en las formas de confrontación; marcos nuevos o transformados para la acción colectiva; una combinación de participación organizada y no organizada; y unas secuencias de interacción intensificada entre disidentes y autoridades que pueden terminar en la reforma, la represión y, a veces, en una revolución». 
variadas y en los lugares más dispares. Y es que resulta casi imposible, en esta época de indignaciones, encontrar un movimiento emancipador que no enarbole su bandera, que no la reivindique y la defienda como suya. El año 2011 marcó un hito en la historia de los movimientos populares ${ }^{3}$ contemporáneos, dando lugar a un descontento social y económico generalizado expresado alrededor del mundo en forma de levantamientos sociales contra los efectos de la crisis mundial desatada en 2008 y la apropiación de la democracia por parte de las oligarquías políticas y económicas para utilizarla en su propio beneficio (Price y Sanz Sabido, 2014; Flesher Fominaya, 2014 a; Sevilla et al., 2011).

La ola de indignación e insatisfacción social explotó en las calles de Tú$n e z^{4}$ y Egipto, extendiéndose hacia otros puntos de Oriente Medio, donde las «primaveras» árabes plantearon reivindicaciones contra el desempleo, la desigualdad, la pobreza, la brutalidad policial, el autoritarismo, la censura y la corrupción. Pero la mecha de la indignación también se encendió en España, Portugal, Grecia, Italia, Chile, Estados Unidos, Canadá, Turquía y Brasil, entre otros lugares, donde han surgido movimientos que operan bajo el estandarte de la «democracia real», tratando de romper con el poder político que las plutocracias, los mercados financieros y las corporaciones empresariales acaparan en los sistemas electorales liberales. En Europa, la gente salió a la calle a protestar contra la degradación socioeconómica generalizada, desafiando las políticas de austeridad implementadas bajo los auspicios de la Unión Europea, el Banco Central Europeo y el Fondo Monetario Internacional (Flesher Fominaya y Cox, 2013; Charnock et al., 2014).

3. Hablo de movimientos populares para evitar su confinamiento a la esfera social, ya que este tipo de movimientos también son económicos y políticos. Es por eso que a menudo son definidos como movimientos populares, puesto que este término incluye todas las dimensiones anteriores.

4. Castells (2012) y Khosrokhavar (2012) identifican las causas que explican el surgimiento de la revuelta en Túnez basándose en tres elementos fundamentales. En primer lugar, la existencia de una masa de desempleados formada por jóvenes graduados, capaz de liderar la revuelta sin pasar por el poder y las estructuras de representación tradicionales. En segundo, una cultura muy fuerte de ciberactivismo, que ayudó a crear un espacio público crítico contra el régimen vigente, con autonomía respecto del Estado. Y por último, una tasa elevada de difusión del uso de Internet, ya sea en los hogares, en cibercafés o espacios educativos, factor que, combinado con la existencia de sectores juveniles con altas calificaciones y sin trabajo, hizo de la juventud el actor principal de la revuelta ciudadana. 
Desde las primaveras árabes hasta las marchas de la dignidad, pasando por el 15M, Occupy Wall Street, la Plataforma de Afectados por la Hipoteca (РAH), los movimientos antiausteridad europeos, como las mareas en España o Que se Lixe a Troika! en Portugal, el movimiento estudiantil chileno, Yo soy 132 en México o el Movimiento Passe Livre en Brasil, la eclosión de movimientos que han tomado las calles y plazas ha supuesto el surgimiento de una crítica renovada del capitalismo y de una conciencia que denuncia la crisis de legitimidad de las instituciones representativas (Tormey, 2014) y cuestiona la manera tradicional de hacer política de los partidos, sindicatos y gobiernos de turno, lo que ha significado la apertura de una ventana de oportunidad para proponer visiones alternativas para el futuro de la democracia (Della Porta, 2013; Graeber, 2013).

Este conjunto heterogéneo de movimientos populares ha sido definido por algunos analistas como «revueltas de indignación», ${ }^{5}$ «movimiento por la democracia real» o luchas por la democracia real (Roos y Oikonomakis, 2013; Hardt y Negri, 2011). Según Roos y Oikonomakis (2013), los movimientos por la democracia real comparten cinco características fundamentales: 1) su autonomía del Estado y el recelo respecto a la política institucionalizada; 2) el uso de métodos horizontales de democracia directa y deliberativa que buscan el consenso y rehúyen de liderazgos individuales; 3) la acción directa, de inspiración anarquista, como postura que desafía a los poderes instituidos, considerados injustos o ilegítimos; 4) el método de ocupación directa y masiva de espacios públicos (plazas, calles, bancos, supermercados, espacios abandonados, facultades universitarias, centros mundiales del poder financiero como Wall Street, etc.); y 5) una política prefigurativa ${ }^{6}$ que apuesta por formas innovadoras y alternativas de organización política, toma de decisiones y sociabilidad, asociadas con un amplio uso de las herramientas y tecnologías

5. Término utilizado por el sociólogo Boaventura de Sousa Santos en la conferencia «Las revueltas mundiales de indignación: su significado para la teoría y para la práctica», pronunciada el 15 octubre de 2013 en el auditorio del Palacio de Comunicaciones de La Paz (Bolivia).

6. Término acuñado por Carl Boggs para referirse a los modos de organización y tácticas que prefiguran o anticipan el futuro de la sociedad que se busca. Alude a la realización, «dentro de la práctica política en curso de un movimiento, de las formas de las relaciones sociales, la toma de decisiones, la cultura y la experiencia humana que constituyen el objetivo final» y contribuyen a la construcción de prácticas políticas más radicales y participativas (Boggs, 1977). 
de la información y la comunicación, en especial las redes sociales como estrategias de movilización (Castells, 2012; Harvey, 2012). Así, más allá de las diferencias específicas que presentan en cada país, los movimientos por la democracia real comparten una serie de prácticas y formas insurgentes de política que reconstruyen la democracia desde abajo a partir del asamblearismo, la horizontalidad, la acción directa, la autogestión sin líderes y la toma de decisiones por consenso.

¿Pero, cómo se manifiesta la radicalidad democrática de las actuales luchas que inciden en las formas comunitarias, horizontales y desjerarquizadas de política? ¿Qué condiciones debe cumplir la democracia real y radical para ser digna de su nombre? En lo que sigue, pretendo abordar estas cuestiones de manera amplia a partir de una serie de reflexiones argumentadas sobre la construcción y definición de un nuevo sentido común democrático derivado de los movimientos populares que han tomado las calles en el contexto de la crisis económica y financiera mundial. Lo que este artículo trata de hacer es explorar y dilucidar las principales características de este sentido común político a partir de una reflexión general sobre las ideas, imaginarios y prácticas democráticas de estos movimientos, planteando la cuestión de cómo están contribuyendo a reinventar la dirección y el sentido de la política. El texto conjuga elementos descriptivos (sobre cómo se están manifestando de hecho las transformaciones desde el activismo político) y normativos (relacionados con las condiciones que idealmente debería cumplir una democracia para ser real) que permiten enfocar a estos movimientos como creadores de democracia radical y germen de un nuevo poder popular no vinculado con el Estado ni con el poder institucional tradicional (Ibarra et al., 2002).

\section{Hacia un nuevo sentido común democrático}

Para abordar las preguntas planteadas en la introducción señalaré en forma de enunciados los - a mi juicio - principales elementos que componen 
dicho sentido común democrático. ${ }^{7}$ Estos elementos no sólo tienen un valor normativo para la reconstrucción teórica y práctica de la democracia. También condicionan las estrategias que limitan los campos de la acción social y política, abriendo un horizonte de cambio social que apunta al surgimiento de nuevas dinámicas de organización, acción y movilización colectiva, nuevas identidades políticas y formas de sociabilidad constructoras de gramáticas de democracia radical que amplían el campo de lo posible (Lummis, 2002).

\section{El nuevo sentido común celebra la diversidad democrática del mundo}

La radicalidad democrática con la que están comprometidos los movimientos por la democracia real exige el reconocimiento de lo que Santos y Avritzer (2003 a: 61) llaman demodiversidad, «la coexistencia pacífica o conflictiva de diferentes modelos y prácticas democráticas». Reconocer la demodiversidad supone, por un lado, desaprender las formas de domesticación política liberal que proclaman la centralidad del voto, las elecciones y la representación como formas de mediación política, canales que han permitido a las élites reproducir a lo largo del tiempo sus sistemas de dominación y explotación. Los movimientos por la democracia real están contribuyendo al desaprendizaje de la democracia liberal como vía transformadora, es decir, al desmantelamiento de las representaciones hegemónicas que presentan la democracia como un producto descontextualizado, desideologizado y naturalizado. Es lo que en términos de análisis puede llamarse el combate contra la monocultura de la democracia liberal: el predominio mundial de una sola práctica y de un único discurso democrático, el de la democracia formal, representativa, electoral y partidocrática globalizada (Aguiló, 2013). Se trata de una monocultura política institucionalizada a escala global tan poderosa que:

7. Gramsci llamó la atención sobre cómo el sentido común constituye un complejo entramado socio-cognitivo que reproduce la ideología dominante. El sentido común, formado por el conjunto de creencias, percepciones, prácticas rutinarias y hábitos de vida compartidos en un determinado momento por un grupo o comunidad, es el canal a través del cual la filosofía (el grado más elaborado de la concepción del mundo de las clases dominantes) se propaga entre los diferentes estratos sociales, que lo naturalizan sin cuestionarlo. El sentido común, escribe Gramsci (1971: 125), aparece, así, como «la filosofía de los "no filósofos", o sea la concepción del mundo absorbida acríticamente de los varios ambientes culturales en medio de los cuales se desarrolla la individualidad moral del hombre medio». 
1. Establece un régimen de visibilidad (un modelo político y epistemológico que separa lo que cuenta como democracia de lo que no) que margina o descalifica las concepciones y prácticas democráticas que se apartan de la ortodoxia (neo)liberal. La monocultura de la democracia liberal invisibiliza o niega, de este modo, la existencia de fenómenos democráticos fuera de la democracia institucional o, en caso de reconocer su existencia, los equipara a manifestaciones de ingobernabilidad, caos o despotismo.

2. Instituye un orden social y político que hace pasar por generales los intereses particulares de las clases dominantes y legitima, por medios políticos, un modelo de sociedad que reproduce su hegemonía. La democracia liberal ha configurado, en este sentido, un marco político que permite instaurar regímenes electorales favorables a los intereses del liberalismo: individualismo, mercados libres, competencia partidaria, igualdad formal, etc.

3. Convierte en canónica la experiencia política de tres países occidentales: Inglaterra (el parlamentarismo, Locke, la revolución Gloriosa de 1688, entre otros fenómenos), Francia (la Ilustración y la revolución de 1789) y Estados Unidos (la Declaración de derechos de Virginia de 1776 y la Constitución Federal de 1787).

4. Presenta la democracia liberal como la «forma final de gobierno humana», según las palabras de Fukuyama (1989); es decir, como un producto culturalmente superior e históricamente acabado.

El predominio mundial del modelo de democracia elitista liberal guarda una estrecha relación con lo que Godelier (1997) llama el proceso de «occidentalización del mundo», o lo que en otros términos Santos (1998 a: 202) llama «localismo globalizado», «un proceso cultural mediante el cual una cultura local hegemónica se come y digiere, como un caníbal, otras culturas subordinadas»».

Por otro lado, el reconocimiento de la demodiversidad también implica reaprender la democracia a partir de experiencias más allá del parlamentarismo y la democracia electoral; experiencias de ayer y hoy invisibilizadas por 
el poder liberal y de las cuales extraer aprendizajes significativos: la Comuna de París, experiencias autogestionarias, las Juntas Zapatistas de Buen Gobierno, el asamblearismo del 15M, los Consejos Sectoriales en Brasil, las mareas, los occupy, los Consejos Comunales en Venezuela, etc. Reconocer estas experiencias no quiere decir valorarlas acríticamente, sino buscar su inclusión en los debates sobre profundización democrática y explorar su potencial para crear formas más exigentes de articulación y decisión política.

\section{El nuevo sentido común genera procesos de resignificación social y cultural de la democracia}

Las luchas por la democracia real son luchas por la resignificación política y social de la democracia; luchas por dar nombre a fragmentos de experiencia no verbalizables en la lengua de la política ortodoxa; luchas por desnaturalizar la semántica de la democracia liberal, que nos ha acostumbrado a concebirla en términos schumpeterianos como un «sistema institucional para la toma de decisiones políticas, donde algunos [individuos] adquieren el poder de decisión mediante una lucha competitiva por los votos del elector» (Schumpeter, 1961: 321).

Así, frente al predominio social e intelectual de la «concepción hegemónica de la democracia» ${ }^{8}$ (Santos y Avritzer, 2003 a), los movimientos por la democracia real han introducido la idea de que la democracia es algo más que representación política y liderazgo partidario. Como dice Negri (2012), han forjado una «nueva imagen de la democracia» que pone en el centro el lenguaje del común, de la autoorganización y del poder popular. La democracia real, desde esta perspectiva, más que como una forma institucionalizada de gobierno, puede entenderse como un conjunto de procesos y luchas sociales que construyen poder popular y crean formas contrahegemónicas de política a su servicio, transformando, si es necesario, las relaciones y estructuras que

8. Un conjunto de teorías sobre el significado de la democracia y la participación política que se consolida durante la primera mitad del siglo $\mathrm{xx}$, con las reflexiones de autores como Weber, Kelsen, Schumpeter y Bobbio, entre otros. Aunque adoptan diferentes formulaciones, las teorías inscritas en la concepción hegemónica de la democracia comparten un mismo enfoque normativo de la democracia, así como la preferencia por un conjunto de mecanismos institucionales desarrollados en el marco de la teoría política liberal. 
impiden el ejercicio de la soberanía popular. No son luchas por conquistar el poder o beneficiarse de él, sino por invertirlo y socializarlo. Son luchas heterogéneas que transforman relaciones desiguales de poder en relaciones de autoridad compartida en todos los ámbitos (Santos, 1998 b: 332): luchas contra formas arcaicas de discriminación como el racismo, el clasismo y la homofobia, luchas contra la opresión patriarcal, contra la subordinación de la clase trabajadora al capital, etc. La democracia real y radical se refiere, por tanto, a formas de organizarse, de vivir y convivir capaces de expropiar el poder de decisión a minorías privilegiadas para promover el autogobierno popular. Esto implica romper con la visión formalista y liberal predominante de la democracia, que la reduce a un procedimiento de participación en la elección de representantes, lo que no conlleva, necesariamente, participar en la toma de decisiones, y mucho menos la redistribución de la riqueza y el poder.

Estas luchas son portadoras de nuevas gramáticas políticas que amplían los espacios y la calidad de la participación; afirman la primacía de lo público y comunitario — «la defensa de lo público hace vivir la democracia», afirma el profesor Lledó (2011) —; acentúan el papel de la deliberación; destacan la importancia de los movimientos emancipadores en los procesos de cambio social; defienden la politización de la economía, orientándola hacia la satisfacción de las necesidades comunes y ampliando la capacidad de intervención del Estado; promueven la rendición de cuentas, el control y la transparencia pública; reclaman democracia interna en los partidos y organizaciones; y combaten los despotismos sociales e institucionales que persisten.

\section{El nuevo sentido común remite a un nuevo modo de ocupar y dar sentido al espacio público}

La democracia liberal parece desconfiar de los espacios de acción política fuera de los canales formales mediante los cuales se ejerce la democracia representativa. La democracia, desde esta lógica institucionalista, se ejerce «con votos y no con pancartas» y se resuelve en las urnas y no «desde una tienda de campaña», tal y como declararon, respectivamente, los entonces di- 
putados del Psoe José Bono ${ }^{9}$ y del pp José Antonio Bermúdez de Castro. ${ }^{10}$ Esto se explica porque la democracia liberal es fruto de una teoría despolitizadora que reduce la acción política al ámbito formal e institucional, fuera del cual se extiende un campo de relaciones y espacios considerados privados a los que les niega cualquier tipo de politicidad.

Por el contrario, los movimientos por la democracia real han redefinido y ampliado los espacios de la política. Han creado una nueva politicidad en lo cotidiano y desde él, abriendo un campo político popular de acción extrainstitucional que reclama nuevos ámbitos y espacios fundados en ejercicios de democracia (experiencias de autoorganización y participación horizontales, inclusivas y plurales) articulados entre las redes y las calles/plazas (Kioupkiolis y Katsambekis, 2014). Lo que se ha producido es una ampliación de los espacios políticos y una democratización del espacio público más allá de los momentos electorales y del sistema parlamentario. Muchos activistas de estos movimientos no sólo han ocupado calles, plazas, bancos y rodeado las instituciones estatales para señalar los espacios públicos privatizados o confiscados por el capitalismo, sino que también han creado espacios de democracia radical y poder popular: acampadas en plazas, asambleas en barrios y pueblos, centros autogestionados, huertos comunitarios, radios comunitarias, etc. (Squatting Europe Kollective, 2013).

\section{El nuevo sentido común involucra nuevas prácticas democráticas y de participación popular}

Estas prácticas no electorales presentan las siguientes características: 1) revelan un alto grado de politización; 2) se producen con una intensidad y duración variables; 3 ) sirven para visibilizar un conflicto, demanda o necesidad específica de la sociedad; y 4) permiten ejercer la participación democrática como una práctica social cotidiana desde abajo. Acampadas en calles

9. Declaraciones de agosto de 2011. Véase: <http://www.publico.es/espana/390233/ bono-los-problemas-no-se-arreglan-desde-una-tienda-de-campana $>$ [Consulta: $10 \mathrm{de}$ junio de 2014].

10. Declaraciones con motivo de las manifestaciones del segundo aniversario del $15 \mathrm{M}$. Véase $\quad<$ http://www.elmundo.es/elmundo/2013/05/14/espana/1368530925.html > [Consulta: 8 de junio de 2014]. 
y plazas, asambleas, escraches,${ }^{11}$ marchas, ocupaciones de lugares públicos, gritos mudos, desobediencias pacíficas, performances artísticas, encierros, caceroladas, plebiscitos populares, entre otras prácticas, muestran la vitalidad de una imaginación democrática generadora de un repertorio de formas de ejercicio del poder popular y ciudadano que desbordan los límites de una democracia insuficiente que no sólo no lo permite, sino que lo reprime e incluso criminaliza (Amnistía Internacional, 2012). Muchas de estas prácticas constituyen lo que puede llamarse acciones rebeldes (Santos, 2003 b: 286), formas de intervención social que se desvían del supuesto orden natural de los acontecimientos porque rompen con lo previsible y lo dado, abriendo espacios de posibilidad y esperanza por parte de sujetos que buscan construir y recrear activamente la Historia, pero también su historia.

Es interesante observar que varias de estas acciones de protesta se construyen sobre lo que, en la línea de la epistemología del Sur de Santos (2009: 113), puede llamarse una ecología de saberes y prácticas democráticas colectivas, es decir, una «agregación de la diversidad a través de la promoción de interacciones sustentables entre entidades parciales y heterogéneas»».

Tomemos el ejemplo de la PAH, que reúne a activistas antidesahucios, abogados, desempleados y trabajadores migrantes, y combina la acción directa (paralización de ejecuciones hipotecarias, ocupando sucursales bancarias y organizando escraches informativos frente a las viviendas de los políticos, acampadas, acciones de sensibilización, etc.) con medidas de presión tradicionales, como la iniciativa legislativa popular, desbordando la lógica clásica de movilización (Parcerisa, 2014: 32; Romanos, 2014). Al mismo tiempo, la PAH trabaja en estrecha colaboración con diferentes grupos y movimientos (como el 15M) dentro de las diferentes coordinadoras estatales.

Consideraciones análogas pueden hacerse respecto al actual movimiento asambleario educativo en Baleares (Borràs Ensenyat et al., 2013). Uno de sus principales exponentes, la Asamblea de Docentes, a quien el Gobierno auto-

11. La propia Audiencia Provincial de Madrid, en su Auto $\mathrm{n}^{\mathrm{o}}$ 81/14, considera que el escrache practicado ante la vivienda de la vicepresidenta del Gobierno español en abril de 2013 es «un mecanismo ordinario de participación democrática de la sociedad civil». Para más información, véase: $<$ http://politica.elpais.com/politica/2014/02/04/actualidad/1391523321 265376.

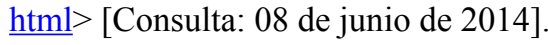


nómico ha venido negando el carácter de interlocutor oficial válido, participa en numerosas acciones coordinadas con los sindicatos tradicionales, con las familias (a través de las asociaciones de padres y madres) y con otros actores institucionales no gubernamentales (Obra Cultural Balear, UCTAIB, etc.).

Una ecología semejante entre distintas prácticas democráticas puede encontrase también en la Candidatura d'Unitat Popular (CUP), que ha sabido conjugar presencia institucional con presencia en la calle, situándose en la primera línea parlamentaria en cuestiones como la lucha contra los desahucios, la corrupción, las balas de goma y el fracking, entre otras, así como llevando a la cámara catalana tanto las reivindicaciones como el vocabulario de los movimientos sociales emancipadores (Castañón, 2013).

De este modo, la radicalización democrática, además de como un punto de partida, aparece también como un proyecto y un horizonte que se realiza a través del encuentro y la articulación entre experiencias parciales y contextuales en construcción de conocimientos, prácticas, espacios, sociabilidades y normatividades alternativas.

\section{El nuevo sentido común incorpora sujetos políticos despolitizados}

El actual ciclo de luchas por la democracia real ha supuesto la entrada en escena de una diversidad de sujetos despolitizados por la democracia liberal y otras teorías políticas que otorgan el privilegio de la representación a actores organizados en las estructuras clásicas de canalización política (partidos, sindicatos $\mathrm{y} \mathrm{ONG})$

Durante el trabajo de campo ${ }^{12}$ realizado en Madrid con asambleas barriales del $15 \mathrm{M}$ y movimientos afines me quedé asombrado al ver participar a gente que prácticamente nunca antes había participado en nada, que nunca había tenido la oportunidad de hablar y ser escuchada. Para muchos era la primera vez que podían formar parte en la toma de una decisión más allá del consumo. Desempleados excluidos del mundo del trabajo y el consumo,

12. Llevado a cabo entre algunos meses de 2013 y 2014 en el marco del proyecto de investigación «Más allá de las urnas: lenguajes y prácticas políticas del $15 \mathrm{M}$ », parte integrante del anteriormente mencionado proyecto ALICE. 
trabajadores precarizados, desahuciados, estudiantes sin futuro, migrantes, pensionistas, entre otros colectivos que denuncian su subrepresentación en las instituciones políticas y su falta de participación en los procesos de toma de decisiones, constituyen un nuevo sujeto social que amplía el radio de la política y revitaliza las formas de organización y práctica política de los movimientos sociales (Sader, 1998). Eran sujetos que no habían sido previstos por los marcos teóricos convencionales, que ignoran o menosprecian la existencia de un sur global no institucional, disperso y a menudo desorganizado en lucha de manera autónoma por derechos políticos y sociales, como la mejora de sus condiciones sanitarias frente a las lógicas privatizadoras del neoliberalismo. De este modo, las luchas por la democracia real han puesto en entredicho la ceguera de una democracia que, a pesar de arrogarse la representación de la ciudadanía, ha mostrado no ser representativa de grandes sectores de la sociedad.

\section{El nuevo sentido común permite formas inéditas de complemen- tariedad democrática orientadas a crear nuevos tipos de articu- lación y decisión política}

Frente a la monocultura de la democracia elitista liberal, los proyectos y luchas para profundizar los procesos de democratización pasan por la generación de prácticas de articulación y complementariedad entre la democracia participativa, radical y representativa.

La complementariedad es un terreno fértil para la creación de formas participativas de política e institucionalidad que produzcan cambios en las relaciones de poder existentes, ayudando a promover el autogobierno y la decisión colectiva. Complementariedad no significa mera combinación de elementos preexistentes de democracia representativa y participativa. La lucha por la radicalidad democrática implica ir más allá de la combinación de elementos previos para construir, mediante un experimentalismo democrático (Unger, 1998) capaz de crear lo nuevo y transformar lo viejo, nuevos espacios donde ensayar prácticas político-sociales basadas en el encuentro, la mezcla y/o la articulación social e institucional entre diferentes formas de democracia.

Al contrario de lo que pudiera parecer, la democracia radical parte de una base experimental e inclusiva que no abdica necesariamente de la dimensión 
representativa. Lo que busca es ampliar y transformar la calidad de la sustancia representativa en sentido contrahegemónico para ponerla al servicio del poder popular y articularla con formas de participación no representativas. De hecho, si analizamos contextos como el español, puede observarse que el 15M es portador de dos almas (Taibo, 2013): una insurgente, autogestionaria, centrada en una perspectiva de largo alcance que hace hincapié en la participación extrainstitucional y en las tendencias horizontales comprometidas con la democracia radical, asamblearia y sin líderes; y otra más inmediatista, con formas de participación híbridas que combinan tendencias horizontales con otras de carácter vertical (jerarquización, burocratización, centralización, etc.). Todo ello permite entender por qué emergen partidos de nuevo cuño como Podemos, ${ }^{13}$ Ganemos y el Partido X, formaciones que optan por la política institucional, aunque incorporando elementos novedosos de carácter horizontal (Flesher Fominaya, 2014 b y 2014 c).

Hay distintos tipos de complementariedad, pero para que se den primero es necesario legitimar la diversidad democrática y crear espacios participativos que devuelvan el poder a la gente. Ya existen casos interesantes de articulación, como el presupuesto participativo o los consejos sectoriales en Brasil. Son formas de participación herederas de la tradición liberal de la ciudadanía pero dotadas de un sentido colectivo que va más allá del liberalismo. Precisamente, uno de los principales retos de las teorías políticas innovadoras es investigar las contradicciones, limitaciones y posibles caminos para encontrar articulaciones y formas de radicalización democrática basadas en la complementariedad que las luchas por la democracia permiten llevar a cabo dentro y fuera de las instituciones: luchas por una nueva cultura electoral, luchas por formas de democracia participativa y deliberativa, luchas por formas de democracia radical, autogestionaria, horizontal, etc.

13. Podemos, que en las últimas encuestas demoscópicas aparece como la primera opción directa en intención de voto en el Estado español (CIS, 2014), surge a principios de 2014 como una alternativa política que recoge buena parte de la rabia y la indignación de la gente con el poder establecido. Después de los buenos resultados obtenidos en las últimas elecciones europeas, en las que la formación obtuvo cinco representantes en el Parlamento europeo, este reciente movimiento social y político ha conseguido, en menos de un año de existencia, poner la política española del revés y representar para muchos la esperanza de construir una alternativa a la política basada en el concepto de casta. 


\section{El nuevo sentido común aspira a desmercantilizar, democratizar y descolonizar la democracia}

Desmercantilizar la democracia significa decir dejar de reducirla a un mercado electoral donde se compran y venden votos por los que compiten los partidos. Es luchar para que los esquemas de libre mercado y sus valores no transformen la democracia en una mercadería. Es rechazar las formas capitalistas y neoliberales de despojo, desposesión (Harvey, 2004) pobreza y desigualdad que vienen globalizándose desde principios de la década de 1980 . Y es también alterar el predominio de la economía sobre la política, fortalecer el control social y situar la democracia por encima del cálculo electoralista y partidista.

Democratizar la democracia quiere decir liberarla de la camisa de fuerza que la acoraza, desbordar los límites que la reducen a una democracia política sin contenido social, alejarla de la mera representación y de la igualdad jurídica formal y apostar, como dice Rancière (apud Benvenuto, 2003: 26), por la democracia como «el poder de los incompetentes», por el poder negado de aquéllos a los que el liberalismo ha tratado históricamente como masas irracionales condenadas a la ineptitud política.

Descolonizar la democracia significa desaprender su matriz eurocéntrica fundada en la perspectiva del varón blanco adulto, burgués, propietario, cristiano y heterosexual; denunciar los sesgos racistas, sexistas y clasistas de una falsa democracia que finge que opresores y oprimidos son iguales en las urnas; reivindicar la demodiversidad y el valor de otras racionalidades políticas frente a la colonialidad de la democracia, que presenta la democracia liberal como forma superior (e insuperable) de organización política.

Para satisfacer estas aspiraciones y reforzar sus luchas es fundamental que los movimientos por la democracia real eviten que sus modelos y prácticas de emancipación se conviertan en un modelo de opresión para los demás. A pesar de la fuerza de lemas como «Somos el 99\%», popularizado por el movimiento Occupy, es importante no caer en posturas homogeneizantes que invisibilicen las diferentes posiciones y condiciones que cada sujeto tiene en la sociedad. Precisamente, las divisiones que existen entre el 99\% y el 1\% restante se basan en relaciones coloniales de dominación, explotación y subordi- 
nación. Resulta poco conveniente hablar de la crisis financiera sin hablar de la importancia de la raza (como constructo social), de la clase social, del género y de la sexualidad en las dinámicas de poder y desigualdad social. Si no llevan a cabo análisis intersectoriales que se ocupen del racismo, del sexismo y el patriarcado, los movimientos pueden salir debilitados. La descolonización de las luchas por la democracia real obliga a ejercerlas sobre la base de diálogos y aprendizajes recíprocos adquiridos a partir de una multiplicidad de espacios y relaciones compartidas con diferentes movimientos y organizaciones. De ahí la importancia de desaprender la colonialidad y sus formas de expresión también en el interior de los movimientos democratizadores.

\section{Conclusiones}

Los movimientos surgidos en el sur global al calor de las recientes olas de indignación están introduciendo cambios efectivos en la forma de entender y practicar la democracia, aunque los contextos y significados que las personas le atribuyen puedan variar. Luchas por la participación política, asambleas populares, desobediencias cívicas pacíficas, demandas de procesos constituyentes y cambios de régimen, entre otros fenómenos, revelan el surgimiento de un incipiente sentido común político basado en lo que, tomando como fuente de inspiración la filosofía política de Castoriadis (2007), puede llamarse una imaginación democrática instituyente y radical. ${ }^{14}$

Este nuevo sentido común político, inscrito en una perspectiva de experimentalismo, diversidad y radicalidad, ha repolitizado la sociedad; ha redefinido el significado social y cultural de la democracia; ha creado espacios contrahegemónicos de construcción política más allá (y a menudo en contra) de los espacios institucionales, impulsando luchas sobre el uso y significado del espacio público; ha originado prácticas democráticas despreciadas por la política liberal; ha promovido formas de sociabilidad alternativa a través de acciones desobedientes (Cruells e Ibarra, 2013); y ha roto el determinismo

14. La imaginación democrática presenta un carácter instituyente y radical cuando desafía las ideas y prácticas democráticas convencionales, reconoce la existencia de sujetos, espacios y saberes democráticos que amplían su significado y alcance tradicional, y cuando es portadora de un horizonte emancipador que apunta a la transformación política, social y cultural. 
histórico-social del «fin de la Historia» (Fukuyama, 1989) proclamado por el neoliberalismo (Badiou, 2012).

Conservar y ampliar los sentidos comunes democráticos de masas surgidos de las luchas populares en calles y plazas del sur global es imprescindible para, en palabras de Gramsci (1984: 305), construir una «nueva cultura» política radical, emancipadora, experimental y demodiversa. Una cultura política que logre superar la idea fatalista de que con la soberanía casi total de los mercados libres y la implantación global de democracia liberal la humanidad ha alcanzado a su punto culminante; que consiga ir más allá de las formas defensivas de lucha contra el capitalismo, el colonialismo y el sexismo, entre otros sistemas de dominación, poniendo en marcha dinámicas ofensivas desde lo institucional y lo social basadas en la complementariedad democrática; que logre intensificar los procesos de creación de poder popular, abriendo otros espacios (el barrio, la escuela, la plaza pública, etc.) para la manifestación política y la democracia más allá de lo electoral y de la deliberación institucional, pues la conquista del poder estatal no implica la conquista del poder social; pero sobre todo, y como base de lo anterior, una cultura política que, como le decía Marx (1982) en su carta a Ruge, sea capaz de clarificar las luchas y aspiraciones del presente.

\section{Referencias}

Aguiló, A. J. (2013): «Una cartografía abismal de la democracia: representación política y democracia de baja intensidad», en Instituto Internacional Casa de Mateus (org.), Representação | Representation. IICM, Vila Real (Portugal), pp. 54-79.

Amnistía Internacional (2012): Actuación policial en las manifestaciones en la Unión Europea. AI: EUR 01/022/2012. Disponible en: <http://www.amnesty.org/es/library/asset/EUR01/022/2012/es/1 ce3a468-55df-4e858200-7881076b5204/eur010222012es.pdf $>$ [acceso: 29/06/2014].

Badiou, A. (2012): The Rebirth of History: Times of Riots and Uprisings, Verso, London.

Benvenuto, A.; C. Lawrence y P. Vermeren (2003): «Entrevista con Jacques Rancière». Revista de Educación y Pedagogía, xv, nº 36, Universidad de Antioquía, Medellín, pp. 15-27. 
Boggs. C. (1977): «Marxism, Prefigurative Communism, and the Problem of Workers». Publicado en Libcom.org el 23 de septiembre de 2010. Disponible en: $<$ https://libcom.org/library/marxism-prefigurative-communism-problem-workers-control-carl-boggs $>$ [acceso: 27/06/2014].

Borràs Ensenyat, R. ET AL. (2013): «Rebelión verde en las Islas Baleares», Sin Permiso, 22 de septiembre de 2013. Disponible en: $<$ http://www. sinpermiso.info/textos/index.php?id=6282> [acceso: 26/06/2014].

Castañón Ares, C. (2013): «La CUP-AE y la regeneración política». Viento Sur. 13 de noviembre de 2013. Disponible en: $<\underline{\text { http://www.viento- }}$ sur.info/spip.php?article8491> [acceso: 29/06/2014].

Castells, M. (2012): Networks of Outrage and Hope: Social Movements in the Internet Age, Polity Press, Cambridge.

Castoriadis, C. (2007): La institución imaginaria de la sociedad, Tusquets, Barcelona.

Centro de Investigaciones Sociológicas (2014): Barómetro de octubre, Avance de resultados, Estudio $n^{\circ} 3.041$, octubre 2014. CIS. Madrid. Disponible en: <http://ep00.epimg.net/descargables/2014/11/05/ f65f19988a09564864ddb9414be2f785.pdf $>$ [acceso: 15/11/2014].

Cruells, M. y P. Ibarra (coords.) (2013): La democracia del futuro. Del $15 \mathrm{M}$ a la emergencia de una sociedad civil viva, Icaria, Barcelona.

Charnock, G.; T. Purcell y R. Ribera-Fumaz (2014): The Limits to Capital in Spain: Crisis and Revolt in the European South, Palgrave Macmillan, New York.

Della Porta, D. (2013): Can Democracy be Saved? Participation, Deliberation and Social Movements, Polity Press, Cambrigde.

Flesher Fominaya, C. (2014 a): Social Movements and Globalization: How Protests, Occupations and Uprisings are Changing the World, Palgrave Macmillan, Basingstoke.

- (2014 b) «Debunking Spontaneity: Spain's 15M/Indignados as Autonomous Movement». Social Movement Studies: Journal of Social, Cultural and Political Protest, 1-22.

- (2014 c): «España es diferente: Podemos y el 15MPart», Público, 09/06/2014. Disponible en: <http://blogs.publico.es/el-cuarto-poder-en-red/2014/06/09/espana-es-diferente-podemos-y-el-15-m/> [acceso: 18/06/2014].

- y Cox, L. (2013): Understanding European Movements: New Social Movements, Global Justice Struggles, Anti-Austerity Protest, Routledge, London. 
Fukuyama, F. (1989): «The End of History?», The National Interest, 16, 3-18.

Godelier, M. (1997): «El Occidente, ¿espejo o espejismo de la evolución de la humanidad? Algunas reflexiones sobre el proceso de occidentalización del mundo y sus vínculos con la evolución de la antropología». En ArizPe, L. (ed.): Las dimensiones culturales del cambio global: Una perspectiva antropológica. Centro Regional de Investigaciones Multidisciplinarias, UNAM, Cuernavaca.

Graeber, D. (2013): The Democracy Project: A History, a Crisis, a Movement, Penguin, London.

Gramsci, A. (1971): El materialismo histórico y la filosofía de Benedetto Croce, Nueva Visión, Buenos Aires.

- (1984): Cuadernos de la cárcel, 3, Ediciones Era, México.

Hardt, M. y T. Negri (2011): «The Fight for «Real Democracy» at the Heart of Occupy Wall Street», Foreign Affairs, October 11, 2011. Disponible en: <http://www.foreignaffairs.com/articles/136399/michael-hardt-and- antonio-negri/the-fight-for-real-democracy-at-theheart-of-occupy-wall-street> [acceso: 17/06/2014].

Harvey, D. (2012): «Os rebeldes na rua: o Partido de Wall Street encontra sua nêmesis». En AAvv: Occupy. Movimentos de protesto que tomaram as ruas, Boitempo-Carta Maior, São Paulo, pp. 57-64.

- (2004): El nuevo imperialismo, Akal, Madrid.

Ibarra, P.; S. Martí y R. Gomà (coords.) (2002): Creadores de democracia radical: movimientos sociales y redes de politicas públicas, Icaria, Barcelona.

Khosrokhavar, F. (2012): The New Arab Revolutions That Shook The World, Paradigm Publishers, London.

Kioupkiolis, A. y G. Katsambekis (2014): Radical Democracy and Collective Movements Today. The Biopolitics of the Multitude versus the Hegemony of the People, Ashgate, London.

Lummis, D. (2002): Democracia radical, Siglo xxi, México.

LLEDó, E. (2011): «¿Quién privatiza a los políticos?», El País, 11/10/2011.

Marx, K. (1982): Escritos de juventud, Fondo de Cultura Económica, México.

Negri, T. (2012): «Qualche questione sullo stato dei movimenti: apriamo la discussione», UniNomade. Disponible en: <http://www.uninomade.org/qualche-questione-sullo-stato-dei-movimenti/> [acceso: 28/06/2014].

Parcerisa, L. (2014): «La PaH: un moviment social contrahegemònic?» Oxímora, Revista Internacional de Ética y Política, 4, 23-40. 
Price, S. y R. Sanz Sabido (eds.) (2014): Contemporary Protest and the Legacy of Dissent, Rowman and Littlefield International, London.

Romanos, E. (2014): «Evictions, Petitions and Escraches: Contentious Housing in Austerity Spain», Social Movement Studies, 13 (2), 296-302.

Roos, J. y L. Oıкоnomakis (2013): «We Are Everywhere! The Autonomous Rootsof the Real Democracy Movement». Paper presentado en el 7th Annual ECPR General Conference 'Comparative Perspectives on the New Politics of Dissent'. Sciences Po Bordeaux, September 4-7, 2013. Disponible en: <https://www.academia.edu/4342422/ The_Autonomous_Roots_of_the_Real_Democracy_Movement $>$ [acceso: 19/06/2014].

SAdER, E. (1998): Quando novos personagens entraram em cena. Experiências e lutas dos trabalhadores da Grande São Paulo (1970-1980), Paz e Terra, Rio de Janeiro.

SAntos, B. S. (1998 a): La globalización del derecho. Los nuevos caminos de la regulación y la emancipación, Universidad Nacional de Colombia-Instituto Latinoamericano de Servicios Legales Alternativos, Bogotá.

- (1998 b): De la mano de Alicia: lo social y lo político en la postmodernidad, Siglo del Hombre Editores/Facultad de Derecho Universidad de los Andes, Bogotá.

- y Avritzer, L. (2003 a): «Introdução: para ampliar o cânone democrático». En SAntos, B. S. (org.): Democratizar a democracia: os caminhos da democracia participativa, Afrontamento, Porto, 35-66.

- (2003 b): Crítica de la razón indolente. Contra el desperdicio de la experiencia. Para un nuevo sentido común: la ciencia, el derecho y la política en la transición paradigmática, Desclée de Brouwer, Bilbao.

- (2009): Una epistemología del Sur: la reinvención del conocimiento y la emancipación social, Siglo XXI/CLACSO, México.

SChumpeter, J. (1961): Capitalismo, socialismo e democracia, Fondo de Cultura/OrdemLivre.org, Rio de Janeiro.

Sevilla, C.; J. Fernández y M. Urbán (eds.) (2011): ¡Ocupemos el mundo! Occupy the Wordl!', Icaria, Barcelona.

Souatting Europe Kollective (2013): Radical Spaces, Urban Struggles, Minor Compositions, Nueva York.

TaIBo, C. (2013): «The Spanish Indignados: A Movement with Two Souls», European Urban and Regional Studies, 20, 155-158.

TARrow, S. (2004): El poder en movimiento: los movimientos sociales, la acción colectiva y la política, Alianza, Madrid. 
Tormey. S. (2014): «The Contemporary Crisis of Representative Democracy», Conference Paper, Australasian Study of Parliament Group. Disponible en: <http:/www.parliament.nsw.gov.au/prod/web/ common.nsf/cbe381f08171c2e8ca256fca007d6044/713b7c74bcb60254ca257d65002c21 ea/\$FILE/ATTVIKXP.pdf/Session $\% 20$ 5\%20-\%20Prof.\%20Simon\%20Tormey\%20-\%20The\%20Contemporary $\% 20$ Crisis $\% 20$ of $\% 20$ Representative $\% 20$ Democracy.pdf $>$ [acceso: 20/06/2014].

Unger, R. (1998): Democracy Realized: The Progressive Alternative, Verso, London. 
